\title{
THE DSM DIAGNOSTIC CRITERIA FOR FEMALE ORGASMIC DISORDER
}

Prepared for the DSM-V Sexual and Gender Identity Disorders Workgroup for DSM-V

Cynthia A. Graham, Ph.D.

January 27, 2009 


\section{INTRODUCTION}

In 1980, the concept of "psychosexual dysfunction" appeared in the third edition of the Diagnostic and Statistical Manual of Mental Disorders (DSM) (American Psychiatric Association, 1980). The term "psychosexual" was chosen to highlight the prevailing assumption at the time that psychological factors were of crucial importance in the etiology of sexual problems (American Psychiatric Association, 1980, p. 261). DSM-III utilized the human sexual response cycle (HSRC) developed by Masters and Johnson (1966) as the framework for classifying sexual dysfunctions, with problems in sexual functioning possible at any one or more of the phases of desire, excitement, orgasm, or resolution. The DSM-III diagnostic criteria for "inhibited female orgasm" are presented in Table 1.

In DSM-IV and DSM-IV-TR (American Psychiatric Association, 1994, 2000), the concept of inhibition no longer featured and accordingly, "Inhibited Female Orgasm" was renamed "Female Orgasmic Disorder" (FOD). The essential feature of the disorder remained the persistent or recurrent delay in, or absence of, orgasm following a normal sexual excitement phase. The major change in DSM-IV-TR was the added requirement that the problem cause "marked distress or interpersonal difficulty" (Criterion B) (see Table 2). One interesting change from DSM-III was the removal of the statement (in Criterion A) that while inability to experience orgasm during coitus in the absence of manual clitoral stimulation might represent a "normal variation of female sexual response," it could indicate a "pathological inhibition" that would justify the diagnosis of inhibited female orgasm. Although there was no explanation provided for why this text was omitted from DSM-IV-TR, presumably it reflected a desire to avoid pathologizing women who experienced orgasm from clitoral stimulation but not from intercourse (Hite, 1976; Tiefer, 2001). Criterion A in DSMIV-TR highlights that "Women exhibit wide variability in the type or intensity of stimulation that triggers orgasm" (p. 506) and there is no attempt to specify the type of stimulation that is 
"normative." As such, women who experience orgasm through clitoral stimulation but not during sexual intercourse do not meet criteria for a clinical diagnosis of FOD (Meston, Levin, Sipski, Hull, \& Heiman, 2004).

In DSM-III-R, subtyping (lifelong or acquired; generalized or situational; psychogenic only or psychogenic and biogenic) was added (American Psychiatric Association, 1987). This subtyping was retained in DSM-IV-TR, although "psychogenic only" vs. "psychogenic and biogenic" was renamed "due to psychological factors" vs. "due to combined factors". Both DSM-III and DSM-IV-TR specified that a diagnosis of FOD would not be given if the orgasmic dysfunction was better accounted for by another Axis I disorder (except another Sexual Dysfunction), or was due exclusively to the direct physiological effects of a substance, or a general medical condition. The requirement that there be a "normal sexual excitement phase" (Criterion A) implies that a diagnosis of FOD should only be made if a woman has not been diagnosed with Female Sexual Arousal Disorder. In fact, however, in the DSM-IV-TR section on "Differential Diagnosis", is the statement "Female Orgasmic Disorder may also occur in association with other Sexual Dysfunctions (e.g., Female Sexual Arousal Disorder).”

In the International Statistical Classification of Diseases and Related Health Problems (ICD-10) (World Health Organization, 1992) “orgasmic dysfunction" (F52.3) is defined as “orgasm either does not occur or is markedly delayed," without any additional diagnostic criteria.

This purpose of this paper is to review the DSM diagnostic criteria for FOD. A brief overview of the concept of female orgasm, including definitional, socio-cultural, psychological, and physiological aspects, will first be presented. Following this, research on the prevalence of FOD and possible etiological factors will be reviewed. Critiques of the DSM criteria will be discussed. The specific diagnostic criteria for FOD will be critically 
examined and key issues that should be considered for DSM-V identified. The paper will conclude with proposed diagnostic criteria for FOD.

\section{BACKGROUND}

"Of all the various sexual responses, orgasm remains the most mysterious and least well-understood." (Bancroft, 2009, p. 84)

Despite the fact that the extensive research on human orgasm has predominantly focused on orgasmic responsiveness in women (Mah \& Binik, 2005; Meston et al., 2004), the above observation is particularly relevant to our understanding of women's orgasm. Unlike orgasm in the male, which is usually accompanied by ejaculation, there is no equivalent objective "marker" of orgasm experienced by women. Indeed women may find that it is difficult to recognize if orgasm has occurred (Bancroft, 2009; Meston et al., 2004). In the male, there is an obvious reproductive function to orgasm, whereas it is generally accepted that female orgasm is not essential for reproduction. Many theories have been put forward for the existence of the female orgasm (Levin, 2005). Lloyd (2005) reviewed these theories and endorsed the evolutionary "by-product" theory advanced by Symons (1979). This postulates that although orgasm has evolved for reproductive reasons in the male, its occurrence in females is due to the fact that there has not been any evolutionary reason to suppress its expression.

\section{Definitions of orgasm}

After an extensive review of the literature, Mah and Binik (2001) concluded that "attempts to propose a universally accepted definition of "orgasm" have met with little success.” (p. 823). The lack of a satisfactory definition of orgasm has been attributed to our limited understanding of the mechanisms underlying orgasm and our reliance on the subjective or self-report aspects of the experience (Meston et al., 2004). Subjective descriptions of orgasm are extremely varied, suggesting that it is experienced in very 
different ways, both across individuals but also on different occasions by the same individual. Some descriptions of orgasm suggest altered consciousness; some describe multiple physical changes, whereas others may be very focused on genital sensations (Vance \& Wagner, 1976). Despite the many gender differences related to orgasm, one early study found that it was not possible to reliably distinguish between male and female written descriptions of orgasm (Vance \& Wagner, 1976).

Early psychoanalytic theory posited that women who required clitoral stimulation to reach orgasm were psychologically less "mature" than those who could reach climax during intercourse (Freud, 1949). Kinsey, Pomeroy, Martin, \& Gebhard (1953) and later, Masters and Johnson (1966) disputed this view, and claimed that all orgasms in women were physiologically identical, regardless of the source of stimulation. There is now good evidence that many women require clitoral stimulation to reach orgasm, and a relatively small proportion report that they always experience orgasm during intercourse (Lloyd, 2005). There are still, however, a few researchers who maintain that "clitoral orgasm" is somehow “inferior" to "vaginal" orgasm (Brody, 2007). Brody and colleagues have suggested that socalled "vaginal" orgasm (as opposed to clitoral orgasm) is associated with less use of “immature” psychological defence mechanisms (Brody \& Costa, 2008), and higher satisfaction with mental health and relationships (Costa \& Brody, 2007).

A number of typologies of orgasm have been proposed (e.g., Fisher, 1973; Singer \& Singer, 1972), many of them differentiating between orgasm experienced following clitoral vs. vaginal stimulation. One long-standing controversy has related to the Grafenberg (or "G"-) spot, an area of erotic sensitivity in the anterior wall of the vagina that in some women may be more responsive to "pressure stimulation" than touch. Levin (2003) concluded that there were likely three "erogenous sites" in this area of the vagina, which he called the 
"anterior wall erogenous complex". What is still unclear is what proportion of women experience localized erotic sensitivity in this area.

In the DSM-IV-TR text on FOD, the orgasm phase is described as “...a peaking of sexual pleasure, with release of sexual tension and rhythmic contraction of the perineal muscles and reproductive organs....In the female, there are contractions (not always subjectively experienced as such) of the wall of the outer third of the vagina. In both genders, the anal sphincter rhythmically contracts.” (p. 494).

There are two noteworthy aspects of the DSM definition. Firstly, apart from the "peaking of sexual pleasure", the description focuses on physiological changes associated with orgasm rather than subjective changes. Mah and Binik (2001) noted a dichotomization of the biological and psychological perspectives on orgasm, with an emphasis on the former. Secondly, the DSM description suggests a "uniformity" of the objective indicators of orgasm, whereas research indicates considerable variability across women (Meston et al., 2004). For example, although Masters and Johnson (1966) asserted that vaginal contractions always occurred with orgasm, later research demonstrated that not all women who reported orgasm showed vaginal contractions (e.g., Bohlen, Held, Sanderson, \& Ahlgren, 1982; Levin \& Wagner, 1985). These contractions also involve the pelvic floor surrounding the vagina, rather than the vaginal wall per se. Similarly, contractions of the anal sphincter accompanying orgasm have been found to occur in only a proportion of women who experience orgasms (Bohlen et al., 1982).

\section{Mechanisms underlying orgasm in women}

While a review of the mechanisms underlying orgasm in women is beyond the scope of this paper (for reviews, see Komisaruk, Beyer-Flores, \& Whipple, 2007 and Meston et al., 2004), an examination of the literature makes it clear that fundamental questions about the mediation of orgasm remain unresolved. For example, the extent to which orgasm is a spinal 
phenomenon, depends on central events, or results from an interaction between central and spinal events is unclear (Bancroft, 2009). It has been reported that approximately $50 \%$ of women following spinal cord injury are able to experience orgasm (Meston et al., 2004), although Sipski, Alexander, and Rosen (2001) found that those with complete lower motor neuron injuries affecting their S2-5 reflex arc were significantly less likely to experience orgasm. There is other evidence that women can experience orgasm with no direct genital stimulation (Heiman, 2007). Studies on brain imaging that have investigated brain activity during orgasm (Komisaruk et al., 2002; Komisaruk \& Whipple, 2005) have suggested that the most important activation sites for orgasm may be the paraventricular nucleus, the central gray area of the midbrain, the cerebellum, and the hippocampus (Heiman, 2007).

\section{Historical and cultural aspects of orgasm}

Heiman (2007) discussed the evolution of medical and societal perspectives on female orgasm and concluded that the current perception of lack of orgasm in women as a problem that requires treatment is in part a "cultural accident" (p. 87). In some historical periods, orgasm in women has not been considered acceptable. In the 1920-30's the emphasis on "marital adjustment" resulted in men thinking that their partners should experience orgasm, putting them under pressure in the process (Dickinson \& Beam, 1931). Many feminists have argued that the current emphasis on women's "right" to orgasm has had negative consequences for women (Potts, 2000; Tiefer, 1991). It has been argued that the undue emphasis on orgasm for women as the goal and "natural" endpoint of sexual activity has been “enshrined" in the DSM (Tiefer, 2001).

In addition to historical shifts, there are also very significant differences across cultures in the perspectives on female orgasm. While few studies have compared prevalence of orgasmic problems in women from different cultures, those that have done so have reported marked cultural differences (e.g., Laumann et al., 2005). In the DSM-IV TR text on 
FOD, there is no mention of cultural factors being an important consideration (although the introductory text on "Sexual Dysfunctions" does state that "Clinical judgments about the presence of a Sexual Dysfunction should take into account the individual's ethnic, cultural, religious, and social background, which may influence sexual desire, expectations, and attitudes about performance.” (p. 495).

\section{Developmental and gender aspects of orgasm}

A woman's first experience of orgasm can occur any time from the prepubertal period to well into adulthood (Bancroft, Herbenick, and Reynolds, 2003). While in boys the age of first orgasm is closely tied to puberty, girls show a much more variable pattern (Kinsey et al., 1953). In Kinsey's original data, $23 \%$ of women reported having experienced orgasm by age $15,53 \%$ by age $20,77 \%$ by age 25 , and $90 \%$ by age 35 . Kinsey estimated that approximately $9 \%$ of women did not experience orgasm throughout their lifetime.

In the U.S. National Health and Social Life Survey (NHSLS), Laumann, Gagnon, Michael, and Michaels (1994) found that women's rates of orgasm consistency (defined as "usually or always" experiencing orgasm) were higher during masturbation than during sexual activity with a partner. About 60 percent of women reported that they "usually" or "always" had an orgasm when masturbating, compared with 29 percent during partnered sex (the corresponding figures for men were $80 \%$ and $75 \%$ ).

One interesting gender difference is that in clinical situations women rarely complain of reaching orgasm too quickly. Reflecting this, there has never been a DSM diagnostic category of "premature orgasm" in women equivalent to "premature ejaculation" in men. Interestingly, however, data from two large-scale surveys indicated that between $6-15 \%$ of women (depending on age) reported that they came to orgasm too quickly (Laumann, Paik, \& Rosen, 1999; Richters, Grulich, de Visser, Smith, \& Rissel, 2003). It is possible that the survey questions used in these two studies (which were similar) were misinterpreted by the 
women respondents. Further research is needed to establish whether reaching orgasm too quickly is a significant problem for women.

\section{PREVALENCE OF ORGASMIC PROBLEMS IN WOMEN}

In the last decade, there have been several large-scale epidemiological surveys that have reported prevalence rates for orgasmic problems in women. Many of these have used nationally representative samples, an improvement over earlier studies that often relied on convenience or clinical samples. In 2001 Simons and Carey reviewed the literature on the prevalence of sexual dysfunction and highlighted several methodological problems. For example, although many studies claimed to have used DSM criteria to establish sexual dysfunction, few assessed the presence of "marked distress or interpersonal difficulty" or the absence of an Axis I disorder (both essential criteria for a DSM diagnosis). More recent studies have made attempts to assess women's distress about sexual difficulties (Bancroft, Loftus, \& Long, 2003; Oberg, Fugl-Meyer, \& Fugl-Meyer, 2003; Shifren, Monz, Russo, Segreti, \& Johannes, 2008; Witting et al., 2008). However, some of the criteria required to make DSM diagnoses are difficult if not impossible to establish in large, population-based surveys (Graham \& Bancroft, 2006). For example, surveys have not assessed whether women have experienced a "normal sexual excitement" phase, a requirement of Criterion A for the diagnosis of FOD. While some researchers have acknowledged that responses to survey questions are not the same as a clinical diagnosis, and because of this have used the term "sexual difficulties" or "sexual problems" rather than "sexual dysfunction" (e.g., Bancroft et al., 2003; Richters et al., 2003), others (e.g., Laumann et al., 1999) have been less cautious. This issue of terminology is an important one, because claims that up to $43 \%$ of American women have a sexual dysfunction (e.g., Laumann et al., 1999) have been widely cited in both the media and the scientific literature (Graham \& Bancroft, 2006). 
Table 3 presents prevalence data on orgasmic problems reported by women from 10 surveys, all of which used nationally representative samples. None of these epidemiological surveys have assessed the prevalence of "lifelong" vs. "acquired" orgasmic problems, but of orgasmic "problems" or "anorgasmia". Both the method of assessment and the time periods assessed differed across studies and not surprisingly, the prevalence estimates of orgasm difficulties also varied widely. Reviewing the evidence from European studies, Fugl-Meyer and Fugl-Meyer (2006) concluded, “... the prevalence of orgasmic dysfunction appears to vary so widely that at the moment there is no conclusive evidence." (p. 35). Although it may not be possible to establish accurate prevalence rates for FOD, there are a number of important aspects related to prevalence and etiology that can be addressed in large-scale surveys (e.g., possible predictors of reported orgasm problems), and these will be discussed further below.

Few surveys assessing prevalence of sexual problems have used psychometrically validated instruments. It is noteworthy here that the only study listed in Table 3 that used a structured psychiatric interview (Lindal \& Stefansson, 1993) reported much lower estimates of anorgasmia (3.5\%) than the other studies. Hayes, Dennerstein, Bennett, \& Fairley (2008) found that the use of simple, non-validated questions (compared with validated, multi-item instruments) resulted in higher estimates for all female sexual disorders.

Although assessed in only a small number of studies, the duration of sexual problems and/or the recall period also clearly affects prevalence rates of orgasmic difficulties. Hayes et al. (2008) found that changing recall from "previous month" to "one month or more in the previous year" increased prevalence rates for all female sexual disorders. In the UK National Survey of Sexual Attitudes and Lifestyles, Mercer et al. (2003) compared prevalence rates for sexual problems reported as lasting at least one month in the past year (referred to here as "short-term") with those lasting at least six months ("persistent problems") in the last year. 
Although $14.4 \%$ of women reported short-term difficulties in experiencing orgasm, only $3.7 \%$ had persistent orgasm problems.

As Table 3 indicates, few surveys have assessed orgasm problems in older women. One exception is the Global Survey of Sexual Attitudes and Behaviors (Laumann et al., 2005) that used computer-assisted telephone interviewing and postal questionnaires to assess sexual problems in 9,000 women aged 40-80 years. Although this study had a number of limitations (e.g., low response rate, differences in recruitment and method of assessment across sites), the findings are of interest because the female respondents were from 29 countries. The prevalence of "inability to reach orgasm" ranged from 17.7\% (in Northern Europe) to $41.2 \%$ (in Southeast Asia). Age was not consistently related to the likelihood of orgasm problems. Other factors e.g, physical health were significant predictors of orgasm difficulties in some countries but not in others, underlining the importance of cultural factors.

\section{Association between Orgasmic Problems and Distress}

Although early surveys rarely assessed reported distress about sexual problems, in recent years researchers have increasingly incorporated questions about personal or interpersonal distress into surveys (e.g., Bancroft et al., 2003; Hayes et al., 2008; King, Holt, \& Nazareth, 2007; Oberg et al., 2004; Shifren et al., 2008; Witting et al., 2008). There have also been self-report measures developed to assess sexual distress e.g., the Female Sexual Distress Scale (FSDS) (Derogatis, Rosen, Leiblum, Burnett, \& Heiman, 2002) and the Sexual Satisfaction Scale for Women (SSS-W) (Meston \& Trapnell, 2005), which includes a subscale measuring distress.

A consistent finding in the literature has been that only a proportion of women experiencing orgasm difficulties also report associated distress (Oberg et al., 2004; King et al., 2007; Shifren et al., 2008; Witting et al., 2008). An early study by Frank, Anderson, and Rubenstein (1978) found that although 63\% of married women reported arousal or orgasm 
problems, $85 \%$ of this group said that they were satisfied with their sexual relationship. Oberg et al. (2004) reported that only $44 \%$ of Swedish women who were categorized as having "manifest" orgasm problems (defined as experiencing orgasm difficulties "quite often" or "nearly all the time") perceived these as "manifestly distressing." In a Finnish survey, Witting et al. (2008) found that while $31 \%$ of women reported orgasm problems, the proportion of women reporting both orgasm problems and distress was only $16 \%$. In a recent U.S. study involving 31,581 women recruited through a national research panel (Shifren et al., 2008), the age-adjusted prevalence of "low orgasm" was $21.8 \%$; the prevalence of orgasm problems with associated distress was much lower (3.4\%-5.8\%, depending on age). Physical health problems and current depression were highly associated with increased odds of orgasm problems.

Bancroft et al. (2003) examined heterosexual women's distress about their sexual relationship and/or their "own sexuality." Of those women who did not experience orgasm, $30-50 \%$ (depending on age) reported marked distress about their sexual relationship. An important finding of this study was that physical aspects of sexual response in women (including orgasm) were relatively weak predictors of distress about sex, while emotional and relationship "well-being" were strong predictors. As the authors concluded, "In general, the predictors of distress about sex did not fit well with the DSM-IV criteria for the diagnosis of sexual dysfunction in women.” (p. 193).

A recent UK study compared ICD-10 diagnoses of women's sexual dysfunction with women's own views of their sexual difficulties (King et al., 2007). The findings suggested a significant discordance between clinical diagnoses and women's experiences of sexual problems. Regarding orgasmic dysfunction, $18 \%$ of the women met ICD-10 criteria, but only $8 \%$ met criteria and also perceived that they had a sexual problem. An even smaller proportion $(5 \%)$ met diagnostic criteria and reported that their inability to experience orgasm 
was a "somewhat" or "very" distressing problem. Women who received an ICD-10 sexual dysfunction diagnosis and themselves considered that they had a problem were more likely to report some homosexual interest. The authors of this study concluded that "DSM-IVTR...misses a significant proportion of women who are distressed by what they regard as sexual difficulties but which do not fit a diagnostic classification.” (p. 287). These findings emphasize the importance of obtaining qualitative data on women's experiences of their sexual difficulties.

While many studies have found associations between orgasmic responsiveness in women and relationship satisfaction (Mah \& Binik, 2001), it is clear that the absence of orgasm does not mean that a woman cannot have a satisfactory and enjoyable sexual relationship. Wellings, Field, Johnson, \& Wadsworth (1994) found fairly similar percentages of women (43.3\%) and men (48.7\%) agreed with the statement "sex without orgasm cannot be really satisfying." The issue of distress seems likely to be related to the degree to which orgasm is important to an individual woman. Here again research indicates considerable variability; orgasm seems to be very important for some women but less important for others (Bancroft, 2009).

\section{Prevalence of FOD in clinical populations}

Although difficult to substantiate, it has been suggested that FOD is less common as a presenting problem than it was during the early days of sex therapy (Heiman, 2007). A number of studies involving clinic populations have identified low sexual interest as the most frequent presenting problem among women, with orgasmic problems frequently cited as the second most common complaint (Warner et al., 1987; Catalan, Hawton, \& Day, 1990; Hirst, Baggaley, \& Watson, 1996; Roy, 2004). In a study of women attending outpatient gynecology clinics, 29\% reported orgasmic problems (Rosen, Taylor, Leiblum, \& Bachmann, 1993). Among UK women attending their general practitioners, a similarly high proportion 
(23\%) reported anorgasmia (Read, King, \& Watson, 1997). Mercer et al. (2003) reported that overall, only $21.0 \%$ of women reporting any sexual problems in the previous year sought help, whereas $31.9 \%$ of women with "persistent" problems (lasting at least six months in the past year) sought treatment.

In considering the literature on the sexual problems for which women and men seek treatment, Bancroft (2009) observed that men more often complain about problems with their genital responses (i.e., erection or ejaculation), whereas women primarily present with complaints about the subjective quality of the sexual experience e.g., lack of interest or pleasure. This issue is very relevant to the DSM-IV classification system for sexual dysfunction, which has largely assumed that women and men experience similar sexual difficulties, and which has also focused on genital responses (lubrication for women and erection for men).

\section{POSSIBLE ETIOLOGICAL FACTORS IN ORGASMIC DYSFUNCTION}

Although many possible causes of orgasmic dysfunction have been proposed, ranging from inadequate tone in the perivaginal muscles (Graber \& Kline-Graber, 1979) to anxiety and distracting thoughts (Dove \& Wiederman, 2000), in most cases the etiology remains uncertain (Heiman, 2007).

\section{Psychosocial factors}

A wide range of psychological factors, such as anxiety and concerns about pregnancy, can potentially interfere with women's ability to reach orgasm. It is clear, however, that there is considerable variability across individual women in how likely they are to be affected by such factors, and we understand little about the reasons for this variability.

Regarding personality factors, in DSM-III (American Psychiatric Association, 1980), "histrionic traits in women" were said to be "frequently associated" with Inhibited Orgasm. In DSM-III-R (American Psychiatric Association, 1987), this text was removed. The DSM- 
IV-TR (American Psychiatric Association, 2000) text includes this statement: "No association has been found between specific patterns of personality traits or psychopathology and orgasmic dysfunction in females." (p. 505). This accords with the research evidence; in a review of the literature, Mah and Binik (2001) concluded, "Overall, associations between female orgasm response and psychopathological adjustment have not been supported.” (p. 834).

Many studies have investigated the relationship between female orgasmic problems and socio-demographic factors such as age, education, marital status, and religiosity, but there have been few consistent findings. The DSM-IV-TR text notes: "Because orgasmic capacity in females increases with age, Female Orgasmic Disorder may be more prevalent in younger women.” (p. 505). While younger age has been associated with greater likelihood of orgasmic difficulties in some studies (e.g., Hawton, Gath, \& Day, 1994; Laumann et al., 1999), other research has either found no relationship between age and orgasm problems (Oberg et al., 2004), or has reported the converse i.e., orgasm problems more common in older women (Richters et al., 2003). Variables that have been more consistently related to experience of orgasmic difficulties (and indeed to most sexual problems in women) have been poor physical and mental health (Bancroft et al., 2003; Laumann et al., 1999; Richters et al., 2003) and relationship difficulties/partner variables (Dennerstein, Lehert, Burger, \& Dudley, 1999; Kelly, Strassberg, \& Turner, 2004).

\section{Physiological factors}

Many physiological factors may influence a woman's ability to experience orgasm, including illnesses, neurological conditions, and some medications (Basson \& Weijmar Schultz, 2007). West, Vinikoor, and Zolhoun (2004) reviewed the evidence on orgasmic dysfunction related to reproductive factors, such as pregnancy and hysterectomy. Although some studies have reported increased orgasm problems after menopause, it has been difficult 
to disentangle the effects of menopause from those of age, partner factors, and psychosocial factors (West et al., 2004). In one population-based sample of American women, menopausal status was not associated with likelihood of orgasm difficulties (Avis, Stellato, Crawford, Johannes, \& Longcope, 2000).

For many years little was known about possible sexual side effects of medications in women, although recently this has changed, with particular attention to the effects of antidepressants (Graham \& Bancroft, in press). Delayed orgasm is the mostly commonly reported side effect of selective serotonin re-uptake inhibitors (SSRIs) in both men and women, affecting between 30-60\% of those using these medications (for reviews, see Montgomery, Baldwin, \& Riley, 2002 and Rosen, Lane, \& Menza, 1999). Rosen et al. (1999) concluded that women taking SSRIs experienced orgasm-related side effects more often than men.

Three studies have explored the role of genetic influences on female orgasmic function in non-clinical samples of women (Dawood, Kirk, Bailey, Andrews, \& Martin, 2005; Dunn, Cherkas, \& Spector, 2005; Harris, Cherkas, Kato, Spector, \& Heiman, 2008). Dunn et al. (2005) compared identical and non-identical twin pairs (4,037 women) from the Twins UK register and found that between $34 \%-45 \%$ of the variation in ability to orgasm could be explained by underlying genetic variation. Recruiting women from the Australian Twin Registry, Dawood et al. (2005) reported that genetic influences accounted for approximately $31 \%$ of the variance of frequency of orgasm during sexual intercourse, and $51 \%$ of the variance of frequency of orgasm during masturbation. More recently, Harris et al. (2008) investigated personality factors and their association with female coital "orgasmic infrequency" in a sample of 2,632 women from the same UK twin register. Introversion, emotional instability, and "not being open to new experiences" were associated with orgasmic infrequency. While these results are intriguing, the authors themselves 
acknowledged that their assessment of orgasm was quite limited and these studies require replication.

\section{CRITIQUES OF DSM-IV-TR CRITERIA FOR FOD}

The DSM-IV classification of sexual disorders in women has received significant criticism (Boyle, 1994; Irvine, 1990; Tiefer, 1996, 2001). Some authors have suggested revised definitions for sexual disorders, while retaining the basic structure of the DSM system i.e., desire, arousal, and orgasm, and pain disorders e.g., Basson et al., 2000; Basson et al., 2003). Others have argued for dismantling the DSM system and replacing it with a new and more women-centered classification (Tiefer, 2001). These various critiques will now be reviewed.

In 2000 the American Foundation for Urologic Disease (AFUD) convened a conference panel, comprising 19 experts who reviewed the DSM-IV criteria for female sexual dysfunction. The Report of the International Consensus Development Conference on Female Sexual Dysfunction (Basson et al., 2000) suggested various revisions to the diagnostic criteria but preserved DSM categories "to maintain continuity in research and clinical practice." (p. 890). For FOD, the addition of "difficulty" in attaining orgasm (as well as possible delay or absence of orgasm) to Criterion A was the only revision suggested. Some researchers and clinicians were critical of the Consensus Committee process and the fact that only minor revisions were advocated, arguing that this reflected an inability to "break out of the DSM-IV confines and develop a new and possibly more useful classification system." (Bancroft, Graham, \& McCord, 2001, p. 98).

In 2002-2003 another AFUD-sponsored international multidisciplinary group was convened to review definitions of women's sexual dysfunction, including those proposed by Basson et al. (2000) a few years earlier, which were now considered "unsatisfactory". A number of recommendations for "expansion and revision" of definitions were provided 
(Basson et al., 2003). Once again the basic structure of the DSM was retained. Regarding FOD, there were only two revisions: the first was the addition of a reduction in orgasmic intensity as part of the criteria, and the second involved a change in sentence structure to emphasize the fact that high or "adequate" sexual arousal was a criterion for the diagnosis of FOD. The revised definition for "Women's Orgasmic Disorder" was: "Despite the self-report of high sexual arousal/excitement, there is either lack of orgasm, markedly diminished intensity of orgasmic sensations, or marked delay of orgasm from any kind of stimulation." (Basson et al., 2003, p. 226). The justification for the inclusion of a reduction in intensity of orgasm was that clinically it is not uncommon to find that women with neurological disease or undergoing chemotherapy report reduced orgasmic intensity (Basson, 2002). The emphasis on "self-report of high sexual arousal/excitement" was added because it was argued that researchers had often ignored the requirement that women diagnosed with FOD must have high or "adequate" arousal. Although Basson et al. (2003) stated that "a DSM-IV diagnosis of orgasmic disorder precludes one of arousal disorder." (p. 226), as discussed above, the DSM text states that FOD may also occur in association with other sexual dysfunctions, including Female Sexual Arousal Disorder (p. 506).

In clinical settings women with lifelong FOD may often also have arousal difficulties although they generally focus on, and seek treatment because of, the lack of orgasm (Basson, 2002). In support of this is research by Andersen and Cyranowski (1995) on sexual arousal in women diagnosed with lifelong FOD. These researchers found that women presenting for treatment with orgasmic problems varied widely in their experience of sexual arousal. They concluded that a number of different "subtypes" of orgasmic dysfunction likely exist and that the proportion of anorgasmic women presenting for treatment who would report unimpaired sexual arousal (i.e., not meeting DSM-IV criteria for Female Sexual Arousal Disorder) would likely be very low. 
Basson (2002) suggested that we reconsider how we define orgasmic 'dysfunction', commenting, "Given that unlike the male response, a woman's orgasm often is not a onepeak event but is a component of her arousal...it would seem helpful to define dysfunctional orgasmic release in terms of arousal itself." (p. 297) (italics added). This issue is one that is relevant to the DSM definition of Female Sexual Arousal Disorder, in that it suggests a possible 'merging' of the different categories of desire, arousal, and orgasm. Basson's suggestion is consistent with Hartmann and colleagues' (2002) argument that female sexual problems should not be conceptualized as discrete phase disorders, but instead as "a global inhibition of sexual response" (p. 79).

Unlike the above recommendations for revising specific DSM diagnostic criteria, the New View of Women's Sexual Problems offered an alternative classification system of women's sexual problems (Kaschak \& Tiefer, 2001). The New View was written by a group of clinicians and social scientists (The Working Group for a New View of Women's Sexual Problems) critical of the DSM taxonomy of sexual disorders. Their primary criticisms of the DSM were that it ignored: gender differences in sexuality, relational aspects of women's sexuality, and individual differences in sexual experience among women. The New View of Women's Sexual Problems (Kaschak \& Tiefer, 2001) provided a "woman-centered" definition of sexual problems as "discontent or dissatisfaction with any emotional, physical, or relational aspect of sexual experience" (p. 5). Unlike the DSM, the New View classification system is not based on symptom criteria, but is instead organized around four possible categories of causes: socio-cultural, political, or economic factors; partner and relationship factors; psychological factors; and medical factors.

Nicholls (2008) examined the degree to which women's accounts of their sexual difficulties accorded with the New View framework. Although this was a small study, involving only 49 women, the findings did support the utility of the New View perspective. 
Although to date this has been the only empirical study that has evaluated the New View classification system, other research provides indirect support for some of its basic tenets e.g., that there is no unitary phenomenon of "dysfunction" and that there is substantial variability in women's experiences. For example, a study by Sand and Fisher (2007) challenged the assumption that there is an underlying "model" of sexual response that is uniform across women. These researchers asked a community sample of nurses which of three different models of sexual response -Masters and Johnson's (1966), Kaplan's (1974), and Basson’s (2000) - best represented their own experience. Approximately equal proportions of women endorsed each of these three models, highlighting the diversity of women's sexual responses.

The above section has outlined some of the critiques of the DSM-IV diagnostic criteria put forward by clinicians and researchers. Before discussing the specifics of the DSM-IV-TR criteria for FOD in more detail, and making some recommendations for change, two key challenges for the classification of sexual dysfunction will be discussed, with a particular focus on how they are relevant to orgasmic difficulties in women. These issues are: (1) how do we best avoid pathologizing normal variation? and (2) how do we effectively acknowledge the relational context of sexual problems? (Mitchell \& Graham, 2007).

As highlighted in this review, there is substantial variability in the capacity for, and experience of, orgasm across women. Women also differ greatly in how important orgasm is to their sexual satisfaction. Given this variability, what strategies might be proposed to avoid pathologizing this normal variation in orgasm?

One strategy that has been adopted is to include a distress criterion as a necessary, but not sufficient, criterion for diagnosing dysfunction. "Marked distress or interpersonal difficulty" is currently an essential criterion for any DSM diagnosis of sexual dysfunction. As discussed above, many studies have found markedly lower prevalence rates for sexual disorders, including orgasmic dysfunction, when distress has been assessed. However, given 
the strong messages from the media about the importance of orgasm, as well as possible expectations/pressure from sexual partners, distress may be engendered even when women experience short-term and/or mild difficulties with orgasm. There are also issues related to the definition/measurement of "marked distress or interpersonal difficulty." Utilizing a dimensional assessment of distress might be helpful in this regard (Widiger \& Samuel, 2005).

Another option is to specify more precise criteria for severity and/or duration of problems and here there have been some specific recommendations put forward. Balon and colleagues (Balon, 2008; Balon, Segraves, \& Clayton, 2007; Segraves, Balon, \& Clayton, 2007) have pointed out that DSM criteria for a number of other disorders include duration of symptoms. Citing the research by Mercer et al. (2003) on persistent vs. short-term problems, these authors proposed that a duration criterion of six months be added to the diagnostic criteria for all sexual disorders. Citing Oberg et al.’s (2004) finding that differentiating between "mild" (defined as "hardly ever" or "quite rarely") vs. manifest ("quite often," "nearly all the time," or "all the time") symptoms resulted in markedly lower prevalence rates of sexual disorders, Balon and colleagues also suggested that more specific severity criteria be considered.

Although clearly more research is needed on the precise severity and duration criteria that should be adopted for DSM-V, it is recommended here that duration and/or severity criteria be added as part of the symptom criteria for FOD.

Turning to the relational context of orgasmic problems, as discussed above, one criticism of the DSM classification of sexual disorders is that it does not sufficiently acknowledge the relational context of sexual problems (Kaschak \& Tiefer, 2001; Mitchell \& Graham, 2007). Although the DSM does note relational processes in the V codes, some have argued that these have been poorly described and have not proven useful for clinical or research purposes (Beach, Wamboldt, Kaslow, Heyman, \& Reiss, 2006). Beach and 
colleagues suggested that another option might be to develop "relationship specifiers". Specifiers are typically used to "describe the course of the disorder or to highlight prominent symptoms" or to "indicate associated behavioral patterns of clinical interest." (Beach et al., 2006; p. 364). With regard to orgasmic disorder, these might include reference to information about the partner of a woman presenting with orgasmic difficulties e.g., whether they have other problems with sexual functioning, are lacking knowledge about sexual techniques. These factors could have major effects on a woman's ability to experience orgasm and this type of information would have clear implications for treatment.

Specific aspects of the DSM-IV-TR criteria for FOD, and the accompanying text, will now be considered, and recommendations made for possible revision.

\section{RECOMMENDATIONS}

\section{DSM-IV-TR text on Female Orgasmic Disorder}

The description of orgasm in the DSM-IV-TR text predominantly focuses on the physiological changes that (may) accompany orgasm in women. The recommendation made here is to "de-emphasize" these physiological aspects of orgasm, for two reasons: firstly, as discussed earlier, the text suggests that physiological changes such as contractions of the anal sphincter invariably occur, whereas research has established that this is not the case (Bohlen et al., 1982). Subjective aspects of orgasm should be better highlighted, as these are the reasons why women seek treatment for orgasm problems (i.e., not because they do not experience contractions of the anal sphincter) and also because assessment of physiological changes that occur during orgasm is not feasible in clinical practice. Secondly, it should be emphasized that both the physiological and the subjective changes experienced during orgasm are extremely variable across women and on different occasions.

DSM-IV-TR diagnostic criteria for Female Orgasmic Disorder 
Criterion A for FOD requires "Persistent or recurrent delay in, or absence of, orgasm following a normal excitement phase." It is recommended that, consistent with suggestions by Balon et al. (2007) and Segraves et al. (2007), specific criteria related to duration and severity be added. This should help to differentiate more persistent sexual problems, which are often (although not always) associated with significant distress, from short-term changes in sexual functioning, which may actually be 'adaptive' reactions in some situations (Bancroft et al., 2003).

The second recommendation is to delete the reference to "a normal excitement phase." As reviewed earlier, the requirement that there be a "normal excitement phase" seems to have engendered considerable confusion. While some researchers and clinicians (e.g., Basson et al., 2003) have erroneously interpreted this to mean that a diagnosis of Female Arousal Disorder precludes a diagnosis of FOD, the DSM-IV-TR text includes a clear statement that both diagnoses can be made. Secondly, there is some evidence (Andersen \& Cyranowski, 1995) that the proportion of women who are anorgasmic and who also report "normal sexual excitement phase" may be very small. Lastly, the phrase "a normal excitement phase" suggests that women's experiences of sexual arousal and orgasm are uniform whereas, as discussed above, there is substantial variability, which should be acknowledged in the DSM text.

Also included in Criterion A is the statement that the diagnosis of FOD "should be based on the clinician's judgment that the woman's orgasmic capacity is less than would be reasonable for her age, sexual experience, and the adequacy of sexual stimulation that she receives." As reviewed earlier, the evidence relating to associations between age and orgasmic difficulties is somewhat inconsistent. However, this statement does reflect the fact that a number of factors need to be considered before a diagnosis of FOD can be made. It is recommended that greater emphasis be placed on the relational aspects of orgasmic problems. 
There is good evidence that women's distress about sexual functioning is significantly associated with relationship problems (King et al., 2007; Witting et al., 2008). Additional text might be added here e.g., on the importance of carefully assessing partner variables (e.g., partner's sexual functioning), and relationship functioning in clinical assessment of women presenting with orgasmic difficulties.

Criterion B requires that "the disturbance cause marked distress or interpersonal difficulty." Issues regarding the distress requirement have been discussed earlier. From a clinical perspective, women who are not distressed by an inability to reach orgasm are unlikely to seek treatment and consequently, would not be given a diagnosis. However, with regard to research, it seems important to assess the presence of distress, as the studies reviewed earlier have consistently documented much higher prevalence rates of orgasmic "dysfunction" when distress is not taken into account. This might be better done using dimensional criteria, rather than (as at present) a categorical assessment of whether distress is present or absent (Regier, 2008; Widiger \& Samuel, 2005), and assessing distress as a "specifier", rather than part of the symptom criteria. The degree of distress that women report from being unable to experience orgasm is extremely variable and assessment of this distress is important for both clinical and research purposes.

Criterion $\mathrm{C}$ requires that "The orgasmic dysfunction is not better accounted for by another Axis I disorder (except another Sexual Dysfunction) and is not due exclusively to the direct physiological effects of a substance (e.g., a drug of abuse, a medication), or a general medical condition.” It is questionable whether it can ever be established whether a sexual dysfunction is due "exclusively" to the effects of a medication or a physical illness. Much of the early research on etiological factors relevant to orgasmic dysfunction focused on the individual woman, with relationship and socio-cultural components largely neglected. In recent years this focus has shifted, with recognition that partner and relationship factors are of 
crucial importance in sexual dysfunction (Byers \& Grenier, 2003; Dennerstein, Lehert, \& Burger, 2005; Fisher, Rosen, Eardley, Sand, \& Goldstein, 2005; King et al., 2007; Oberg et al., 2004). It is recommended that Criterion $\mathrm{C}$ be revised to acknowledge the fact that in many cases of orgasmic problems in women, the causes of orgasmic disorders are multifactorial, or cannot be determined.

\section{DSM-IV-TR Diagnostic Subtypes}

As outlined above, DSM-IV-TR provides subtypes to indicate "the onset, context, and etiological factors" (p. 494) associated with a particular sexual dysfunction. These subtypes are: Lifelong vs. Acquired; Generalized vs. Situational; and Due to Psychological Factors vs. Due to Combined Factors.

For both clinical and research purposes, the distinction between "lifelong" and "acquired" orgasmic problems seems useful. A key issue in the clinical context is to assess an individual woman's capacity for orgasm and whether she has been able to experience orgasm in the past. The recommendation here is that this distinction be retained. It should be noted, however, that the terminology used in the literature to refer to this distinction has been inconsistent, with some authors (e.g., Heiman, 2007) using the term "primary anorgasmia" rather than "lifelong anorgasmia" to refer to women who have never been able to experience orgasm.

The "Generalized" vs. "Situational” subtypes have some clinical utility. In clinical situations, differentiating between women who lack the capacity for experiencing orgasm, and those who have some degree of capacity, but require specific and sufficiently intense (or highly specific) stimulation, to experience orgasm, seems important. This distinction can be helpful in guiding decisions about formulation and treatment. It is important, however, that "situational" is not misinterpreted to mean experience of orgasm with clitoral stimulation but not during vaginal intercourse. In the revised text on FOD, it should be made explicit that 
women who experience orgasm during clitoral stimulation, but not during vaginal-penile intercourse, do not meet criteria for "orgasmic disorder".

The final subtypes, "Due to Psychological Factors" and "Due to Combined Factors," are of little clinical or research relevance. In practice it is often very difficult to establish causation of orgasmic problems with any certainty (Heiman, 2007) and, as discussed above, there is increasing recognition that both psychological and physical factors are often implicated in the causation of sexual dysfunction (Basson \& Weijmar Schultz, 2007). The recommendation made here is to consider removing these subtypes from the FOD category.

Table 4 contains proposed diagnostic criteria for orgasmic disorder in women.

\section{FURTHER RESEARCH}

This review has highlighted a number of issues related to the diagnosis of FOD that require further research. Firstly, research is needed to assess the validity and reliability of adopting more specific duration and severity criteria for diagnosing orgasmic disorders in women. These should be assessed in conjunction with distress criteria, to establish their differential utility. Oberg et al. (2004) suggested that severity criteria might provide more important information than distress criteria. Research should also be done to examine the validity and reliability of adopting "relationship specifiers" in the diagnosis of FOD.

Regarding the subtypes of "lifelong" vs. "acquired" orgasmic disorder, the DSM-IV text on FOD included this statement: "Most female orgasmic disorders are lifelong, rather than acquired. Once a female learns how to reach orgasm, it is uncommon for her to lose that capacity.” (p. 505). As discussed earlier, we have little empirical data on the prevalence of lifelong vs. acquired orgasmic problems.

Basson (2002) recommended inclusion of possible changes in orgasm intensity to diagnostic criteria for FOD. Apart from research on the effects of physical illness or medication on orgasmic functioning, there appears to have been little attention to this aspect 
of orgasm. It seems important to acknowledge that orgasm is not an "all-or-nothing" phenomenon, and that diminished intensity of orgasm may be a problem for some women. On the other hand, we should avoid pathologizing normal variation in the experience of orgasm. A dimensional approach would seem to be the best option to assess the "quality" of orgasm.

One important "gap" in previous research is the lack of information on orgasmic difficulties experienced by women who self-identify as lesbian or bisexual. Most previous studies of prevalence rates of FOD, for example, have included only heterosexual women. Future studies should endeavour to include women of different sexual orientations in studies on orgasm. Lastly, much more research is needed on women's experience of orgasm and reported orgasmic problems, in different cultures. 


\section{REFERENCES}

American Psychiatric Association. (1980). Diagnostic and statistical manual of mental disorders (3rd ed.). Washington, DC: Author.

American Psychiatric Association. (1987). Diagnostic and statistical manual of mental disorders (3rd ed., rev.). Washington, DC: Author.

American Psychiatric Association. (1994). Diagnostic and statistical manual of mental disorders (4th ed.). Washington, DC: Author.

American Psychiatric Association. (2000). Diagnostic and statistical manual of mental disorders (4th ed., text rev.). Washington, DC: Author.

Andersen, B. L., \& Cyranowski, J. M., (1995). Women's sexuality: Behaviors, responses, and individual differences. Journal of Consulting and Clinical Psychology, 63, 891-906.

Avis, N. E., Stellato, R., Crawford, S., Johannes, C., \& Longcope, C. (2000). Is there an association between menopause status and sexual functioning? Menopause, 7, 297309.

Balon, R. (2008). The DSM criteria of sexual dysfunction: Need for a change. Journal of Sex and Marital Therapy, 34, 186-197.

Balon, R., Segraves, R. T., \& Clayton, A. (2007). Issues for DSM-V: Sexual dysfunction, disorder, or variation along normal distribution: Toward rethinking DSM criteria of sexual dysfunctions. American Journal of Psychiatry, 164, 198-200.

Bancroft, J. (2009). Human sexuality and its problems (3rd ed.). Edinburgh: Churchill Livingston/Elsevier.

Bancroft, J., Herbenick, D., \& Reynolds, M. (2003). Masturbation as a marker of sexual development. In J. Bancroft (Ed.), Sexual development in childhood (pp. 156-185). Bloomington: Indiana University Press. 
Bancroft, J., Graham, C. A., \& McCord, C. (2001). Conceptualizing women's sexual problems. Journal of Sex and Marital Therapy, 27, 95-103.

Bancroft, J., Loftus, J., \& Long, J. S. (2003). Distress about sex: A national survey of women in heterosexual relationships. Archives of Sexual Behavior, 32, 193-208.

Basson, R. (2000). The female sexual response: A different model. Journal of Sex and Marital Therapy, 26, 51-64.

Basson, R. (2002). Are our definitions of women's desire, arousal, and sexual pain disorders too broad and our definition of orgasmic disorder too narrow? Journal of Sex and Marital Therapy, 28, 289-300.

Basson, R., Althof, S., Davis, S., Fugl-Meyer, K., Goldstein, I., Leiblum, S., et al. (2004). Summary of the recommendations on sexual dysfunctions in women. Journal of Sexual Medicine, 1, 24-34.

Basson, R., Berman, J., Burnett, A., Derogatis, L., Ferguson, D., Fourcroy, J., et al. (2000). Report of the International Consensus Development Congress on Female Sexual Dysfunction: Definitions and classifications. Journal of Urology, 163, 888-893.

Basson, R., Leiblum, S., Brotto, L., Derogatis, L., Fourcroy, J., Fugl-Meyer, K., et al. (2003). Definitions of women's sexual dysfunction reconsidered: Advocating expansion and revision. Journal of Psychosomatic Obstetrics and Gynaecology, 24, 221-229.

Basson, R., \& Weijmar Schultz, W. (2007). Sexual sequelae of general medical disorders. Lancet, 369, 350-352.

Beach, S. R. H., Wamboldt, M. Z., Kaslow, N. J., Heyman, R. E., \& Reiss, D. (2006). Describing relationship problems in DSM-V: Toward better guidance for research and clinical practice. Journal of Family Psychology, 20, 359-368. 
Bohlen, G. J., Held, J. P., Sanderson, M. O., \& Ahlgren, A. (1982). The female orgasm: Pelvic contractions. Archives of Sexual Behavior, 11, 367-386.

Boyle, M. (1994). Gender, science, and sexual dysfunction. In T. R. Sarbin \& J. I. Kituse (Eds.), Constructing the social (pp. 101-118). London: Sage Publications.

Brody, S. (2007). Vaginal orgasm is associated with better psychological function. Sexual and Relationship Therapy, 22, 173-191.

Brody, S., \& Costa, R. M. (2008). Vaginal orgasm is associated with less use of immature psychological defence mechanisms. Journal of Sexual Medicine, 5, 1167-1176.

Byers, E. S., \& Grenier, G. (2003). Premature or rapid ejaculation: Heterosexual couples' perceptions of men's ejaculatory behavior. Archives of Sexual Behavior, 32, 261-270.

Catalan, J., Hawton, K., \& Day, A. (1990). Couples referred to a sexual dysfunction clinic: Psychological and physical morbidity. British Journal of Psychiatry, 156, 61-67.

Costa, R. M., \& Brody, S. (2007). Women's relationship quality is associated with specifically penile-vaginal intercourse orgasm and frequency. Journal of Sex and Marital Therapy, 33, 319-327.

Dawood, K., Kirk, K. N., Bailey, J. M., Andrews, P. W., \& Martin, N. G. (2005). Genetic and environmental influences on the frequency of orgasm in women. Twin Research and Human Genetics, 8, 27-33.

Dennerstein, L., Lehert, P., \& Burger, H. (2005). The relative effects of hormones and relationship factors on sexual function of women through the natural menopausal transition. Fertility and Sterility, 84, 174-180.

Dennerstein, L., Lehert, P., Burger, H., \& Dudley, E. (1999). Factors affecting sexual functioning of women in the mid-life years. Climacteric, 2, 254-262.

Derogatis, L. R., Rosen, R., Leiblum, S., Burnett, A., \& Heiman, J. (2002). The Female Sexual Distress Scale (FSDS): Initial validation of a standardized scale for assessment 
of sexually related personal distress in women. Journal of Sex and Marital Therapy, 28, 317-330.

Dickinson, R. L., \& Beam, I. (1931). A thousand marriages. Baltimore: Williams \& Wilkins.

Dove, N. L., \& Wiederman, M. W. (2000). Cognitive distraction and women's sexual functioning. Journal of Sex and Marital Therapy, 26, 67-78.

Dunn, K. M., Cherkas, L. F., \& Spector, T. D. (2005). Genetic influences on variation in female orgasmic function: A twin study. Biology Letters, 1, 260-263.

Fisher, S. (1973). The female orgasm. New York: Basic Books.

Fisher, W. A., Rosen, R. C., Eardley, I., Sand, M., \& Goldstein, I. (2005). Experience of Female Partners of Men with Erectile Dysfunction: The Female Experience of Men's Attitudes to Life Events and Sexuality (FEMALES) Study. Journal of Sexual Medicine, 2, 675-684

Frank, E., Anderson, C., \& Rubinstein, D. (1978). Frequency of sexual dysfunction in “normal” couples. New England Journal of Medicine, 299, 111-115.

Freud, S. (1949). Three essays on the theory of sexuality. London: Imago (J. Strachey, Trans., original work published 1905).

Fugl-Meyer, A. R., \& Fugl-Meyer, K. S. (2006). Prevalence data in Europe. In I. Goldstein, C. M. Meston, S. R. Davis, \& A. M. Traish (Eds.), Women's sexual function and dysfunction: Study, diagnosis and treatment (pp. 34-41). Abingdon, Oxon: Taylor \& Francis.

Fugl-Meyer, A. R., \& Fugl-Meyer, K. S. (1999). Sexual disabilities, problems and satisfaction in 18-74 year old Swedes. Scandinavian Journal of Sexology, 2, 79-10.

Graber, B., \& Kline-Graber, G. (1979). Female orgasm: Role of pubococcygeus muscle. Journal of Clinical Psychiatry, 40, 33-39.

Graham, C. A., \& Bancroft, J. (2006). Assessing the prevalence of female sexual dysfunction 
with surveys: What is feasible? In I. Goldstein, C. M. Meston, S. R. Davis, \& A. M. Traish (Eds.), Women's sexual function and dysfunction: Study, diagnosis and treatment (pp. 52-60). Abingdon, Oxon: Taylor \& Francis.

Graham, C. A., \& Bancroft, J. (in press). The sexual dysfunctions. In M. Gelder, J. LopezIbor, N. Andreasen, and J. Geddes (Eds.), New Oxford textbook of psychiatry (2nd. ed.) (Eds). Oxford: Oxford University Press.

Harris, J. M., Lynn, F., Cherkas, L. F., Kato, B. S., Heiman, J. R., \& Spector, T. D. (2005). Normal variations in personality are associated with coital orgasmic infrequency in heterosexual women: A population-based study. Journal of Sexual Medicine, 5, 11771183.

Hartmann, U., Heiser, K., Ruffer-Hesse, C., \& Kloth, G. (2002). Female sexual desire disorders: Subtypes, classification, personality factors and new directions for treatment. World Journal of Urology, 20, 79-88.

Hawton, K., Gath, D., \& Day, A. (1994). Sexual function in a community sample of middleaged women with partners: Effects of age, marital, socio-economic, psychiatric, gynecological, and menopausal factors. Archives of Sexual Behavior, 23, 375-395.

Hayes, R. D., Dennerstein, L., Bennett, C. M., \& Fairley, C. K. (2008). What is the 'true' prevalence of female sexual dysfunctions and does the way we assess these conditions have an impact? Journal of Sexual Medicine, 5, 777-787.

Heiman, J. R. (2007). Orgasmic disorders in women. In S. R. Leiblum (Ed.), Principles and practices of sex therapy (pp. 84-123). New York: Guilford.

Hirst, J. F., Baggeley, M. R., \& Watson, J. P. (1996). A four-year survey of an inner-city psychosexual clinic. Sexual and Marital Therapy, 11, 19-36.

Hite, S. (1976). The Hite Report. New York: MacMillan. 
Irvine, J. (1990). Disorders of desire: Sex and gender in modern American sexology. Philadelphia: Temple University Press.

Kaplan, H. S. (1974). The new sex therapy. New York: Brunner/Mazel.

Kaschak, E. \& L. Tiefer (Eds.) (2001). A new view of women's sexual problems. New York: Haworth Press.

Kelly, M. P., Strassberg, D. S., \& Turner, C. M. (2004). Communication and associated relationship issues in female anorgasmia. Journal of Sex and Marital Therapy, 30, 263-276.

King, M., Holt, V., \& Nazareth, I. (2007). Women's views of their sexual difficulties: Agreement and disagreement with clinical diagnoses. Archives of Sexual Behavior, $36,281-288$.

Kinsey, A. C., Pomeroy, W. B., Martin, C. E., \& Gebhard, P. H. (1953). Sexual behavior in the human female. Philadelphia: W. B. Saunders.

Komisaruk, B. R., \& Whipple, B. R. (2005). Functional MRI of the brain during orgasm. Annual Review of Sex Research, 15, 1-25.

Komisaruk, B. R., Whipple, B. R., Crawford, A., Grimes, S., Kalnin, A. J., Moseir, K., et al. (2002). Brain activity (MRI and PET) during orgasm in women, in response to vaginocervical self-stimulation. [Abstract]. Society for Neuroscience, 841, 17.

Komisaruk, B. R., Beyer-Flores, C., \& Whipple, B. (2007). The science of orgasm. Baltimore: The Johns Hopkins University Press.

Laumann, E. O., Gagnon, J. H., Michael, R. T., \& Michaels, S. (1994). The social organization of sexuality: Sexual practices in the United States. Chicago: University of Chicago Press. 
Laumann, E. O., Paik, A., Rosen, R. C. (1999). Sexual dysfunctions in the United States: Prevalence and predictors. Journal of the American Medical Association, 281, 537544.

Laumann, E. O., Nicolosi, A., Glasser, D. B., Paik, A., Gingell, C, Moreira, E., \& Wang, T. (2005). Sexual problems among women and men aged 40-80 years: Prevalence and correlates identified in the Global Study of Sexual Attitudes and Behaviors. International Journal of Impotence Research, 17, 39-57.

Levin, R. J. (2003). The G-spot-reality or illusion? Sexual and Relationship Therapy, 18, 117-119.

Levin, R. J. (2005). Sexual arousal: Its physiological roles in human reproduction. Annual Review of Sex Research, 16, 154-189.

Levin, R. J., \& Wagner, G. (1985). Orgasm in women in the laboratory: Quantitative studies on duration, intensity, latency and vaginal blood flow. Archives of Sexual Behavior, $14,439-450$.

Lindal, E., \& Stefànsson, J. G. (1993). The lifetime prevalence of psychosexual dysfunction among 55 to 57-year-olds in Iceland. Social Psychiatry and Psychiatric Epidemiology, 28, 91-95.

Lloyd, E. A. (2005). The case of the female orgasm: Bias in the science of evolution. Cambridge, MA: Harvard University Press.

Mah, K., \& Binik, Y. M. (2001) The nature of human orgasm: A critical review of major trends. Clinical Psychology Review, 21, 823-856.

Mercer, C. H., Fenton, K. A., Johnson, A. M., Wellings, K., Macdowall, W., McManus, S., et al. (2003). Sexual function problems and help seeking behaviour in Britain: National probability sample survey. British Medical Journal, 327, 426-427.

Masters, W. H., \& Johnson, V. E. (1966). Human sexual response. Boston: Little, Brown. 
Meston, C., \& Trapnell, P. (2005). Development and validation of a five-factor sexual satisfaction and distress scale for women: The Sexual Satisfaction Scale for Women (SSS-W). Journal of Sexual Medicine, 2, 66-81.

Meston, C. M., Levin, R. J., Sipski, M. L., Hull, E. M., \& Heiman, J. R. (2004). Women's orgasm. Annual Review of Sex Research, 15, 173-257.

Mitchell, K., \& Graham, C. A. (2007). Two challenges for the classification of sexual dysfunction. Journal of Sexual Medicine, 5, 1552-1558.

Montgomery, S. A., Baldwin, D. S., \& Riley, A. (2002). Antidepressant medications: A review of the evidence for drug-induced sexual dysfunction. Journal of Affective Disorders, 69, 119-140.

Najman, J. M., Dunne, M. P., Boyle, F. M., Cook, M. D., \& Purdie, D. M. (2003). Sexual dysfunction in the Australian population. Australian Family Physician, 32, 951-954.

Nicholls, L. (2008). Putting the New View classification scheme to an empirical test. Feminism and Psychology, 18, 515-526.

Oberg, K., Fugl-Meyer, A. R., \& Fugl-Meyer, K. S. (2004). On categorization and quantification of women's sexual dysfunctions: An epidemiological approach. International Journal of Impotence Research, 16, 261-269.

Potts, A. (2000). Coming, coming, gone: A feminist deconstruction of heterosexual orgasm. Sexualities, 3, 55-76.

Read, S., King, M., \& Watson, J. (1997). Sexual dysfunction in primary medical care: Prevalence, characteristics and detection by the general practitioner. Journal of Public Health Medicine, 19, 387-391.

Regier, D. A. (2008). Dimensional approaches to psychiatric classification. In J. E. Helzer, H. C. Kraemer, R. F., Krueger, H-U. Wittchen, P. J. Sirovatka, \& D. A. Regier (Eds.), 
Dimensional approaches in Diagnostic Classification (pp. xvii-xxvii). Arlington: American Psychiatric Association.

Richters, J., Grulich, A. E., de Visser, R. O., Smith, A. M. A., \& Rissel, C. E. (2003). Sexual difficulties in a representative sample of adults. Australian and New Zealand Journal of Public Health, 27, 164-170.

Rosen, R. C., Taylor, J. F., Leiblum, S. R., \& Bachmann, G. A. (1993). Prevalence of sexual dysfunction in women: Results of a survey study of 329 women in an outpatient gynaecological clinic. Journal of Sex and Marital Therapy, 19, 171-188.

Rosen, R. C., Lane, R. M., \& Menza, M. (1999). Effects of SSRIs on sexual function: A critical review. Journal of Clinical Psychopharmacology, 19, 67-85.

Roy, J. (2004). A survey of Relate psychosexual therapy clients. Sexual and Relationship Therapy, 19, 155-166.

Sand, M., \& Fisher, W. A. (2007). Women's endorsement of models of female sexual response: The nurses' sexuality study. Journal of Sexual Medicine, 4, 708-719.

Segraves, R. T., Balon, R., \& Clayton, A. (2007). Proposal for changes in diagnostic criteria for sexual dysfunctions. Journal of Sexual Medicine, 4, 567-580.

Shifren, J. L., Monz, B. U., Russo, P. A., Segreti, A., \& Johannes, C. B. (2008). Sexual problems and distress in United States women. Obstetrics and Gynecology, 112, 970978.

Simons, J. S., \& Carey, M. P. (2001). Prevalence of sexual dysfunctions: Results from a decade of research. Archives of Sexual Behavior, 30, 177-219.

Singer, J., \& Singer, I. (1972). Types of female orgasm. Journal of Sex Research, 8, 255-267.

Sipski, M. L., Alexander, C. J., \& Rosen, R. C. (2001). Sexual arousal and orgasm in women: Effects of spinal cord injury. Annals of Neurology, 49, 35-44.

Symons, D. (1979). The evolution of human sexuality. Oxford: Oxford University Press. 
Spira, A., Bajos, N., \& The ACSF Group. (1994). Sexual behaviour and AIDS. Hants, England: Avebury.

Tiefer, L. (1991). Historical, scientific, clinical, and feminist criticisms of "The human sexual response cycle" model. Annual Review of Sex Research, 2, 1-23.

Tiefer, L. (2001). Arriving at a "New View” of women's sexual problems: Background, theory, and activism. In E. Kaschak \& L. Tiefer (Eds.), A new view of women's sexual problems (pp. 63-98). New York: Haworth Press.

Vance, E. B., \& Wagner, N. N. (1976). Written descriptions of orgasm: A study of sex differences. Archives of Sexual Behavior, 5, 87-98.

Ventegodt, S. (1998). Sex and the quality of life in Denmark. Archives of Sexual Behavior, 27, 295-307.

Warner, P., Bancroft, J., members of the Edinburgh Human Sexuality Group. (1987). A regional clinical service for sexual problems: A three-year survey. Sexual and Marital Therapy, 2, 115-126.

Wellings, K., Field, J., Johnson, A., \& Wadsworth, J. (1994). Sexual behaviour in Britain. London: Penguin Books.

West, S. L., Vinikoor, L. C., \& Zolhoun, D. (2004). A systematic review of the literature on female sexual dysfunction prevalence and predictors. Annual Review of Sex Research, $15,40-172$.

Widiger, T. A., \& Samuel, D. B. (2005). Diagnostic categories or dimensions? A question for the Diagnostic and Statistical Manual of Mental Disorders-Fifth Edition. Journal of Abnormal Psychology, 114, 494-504.

Witting, K., Santtila, P., Varjonen, M., Jern, P., Johansson, A., von der Pahlen, B., \& Sandnabba, K. (2008). Female sexual dysfunction, sexual distress, and compatibility with partner. Journal of Sexual Medicine, 5, 2587-2599. 
World Health Organization. (1992). ICD-10: International Statistical Classification of Diseases and Related Health Problems (10th ed). Geneva: Author. 
Table 1.

DSM-III Diagnostic Criteria for Inhibited Female Orgasm (302.73)

A. Recurrent and persistent inhibition of the female orgasm as manifested by a delay in or absence of orgasm following a normal sexual excitement phase during sexual activity that is judged by the clinician to be adequate in focus, intensity, and duration. The same individual may also meet the criteria for Inhibited Sexual Excitement if at other times there is a problem with the excitement phase of sexual activity. In such cases both categories of Psychosexual Dysfunction should be noted.

Some women are able to experience orgasm during noncoital clitoral stimulation, but are unable to experience it during coitus in the absence of manual clitoral stimulation. There is evidence to suggest that in some instances this represents a pathological inhibition that justifies this diagnosis whereas in other instances it represents a normal variation of the female sexual response. This difficult judgment is assisted by a thorough sexual evaluation, which may even require a trial of treatment.

B. The disturbance is not caused exclusively by organic factors (e.g., physical disorder or medication) and is not due to another Axis I disorder. 
Table 2.

DSM-IV Diagnostic Criteria for Female Orgasmic Disorder (302.73)

A. Persistent or recurrent delay in, or absence of, orgasm following a normal sexual excitement phase. Women exhibit wide variability in the type or intensity of stimulation that triggers orgasm. The diagnosis of Female Orgasmic Disorder should be based on the clinician's judgment that the woman's orgasmic capacity is less than would be reasonable for her age, sexual experience, and the adequacy of sexual stimulation she receives.

B. The disturbance causes marked distress or interpersonal difficulty.

C. The orgasmic dysfunction is not better account for by another Axis I disorder (except another sexual dysfunction) and is not due exclusively to the direct physiological effects of a substance (e.g., a drug of abuse, a medication) or a general medical condition. 
Table 3.

Prevalence of Orgasm Problems in Selected Epidemiological Studies.

\begin{tabular}{|c|c|c|c|c|c|c|}
\hline Study & $\mathrm{N}$ of women & Country & Age & Method of assessment & Time period & Prevalence \\
\hline $\begin{array}{l}\text { Bancroft et al., } \\
2003\end{array}$ & $\begin{array}{l}987 \\
\text { all in heterosexual } \\
\text { relationship }\end{array}$ & $\begin{array}{l}\text { United } \\
\text { States }\end{array}$ & $20-65$ & $\begin{array}{l}\text { Computer-assisted } \\
\text { telephone interviewing }\end{array}$ & $\begin{array}{l}\text { Previous } \\
\text { month }\end{array}$ & $\begin{array}{l}\text { Orgasm during sexual activity with } \\
\text { partner (\% of occasions) } \\
\text { None: } 9.7 \% \\
<25: 11.4 \% \\
25-50: 23.1 \% \\
51-75: 20.1 \% \\
>75: 35.7 \%\end{array}$ \\
\hline $\begin{array}{l}\text { Laumann et al., } \\
1999\end{array}$ & $\begin{array}{l}1,749 ; \text { all sexually } \\
\text { active over last } 12 \\
\text { mos. }\end{array}$ & $\begin{array}{l}\text { United } \\
\text { States }\end{array}$ & $18-59$ & Face-to-face interview & $\begin{array}{l}\text { Several mos. } \\
\text { or more } \\
\text { during past } 12 \\
\text { mos. }\end{array}$ & Unable to experience orgasm: $25.7 \%$ \\
\hline $\begin{array}{l}\text { Lindal \& } \\
\text { Stefansson, } \\
1993\end{array}$ & 421 & Iceland & $55-57$ & $\begin{array}{l}\text { Face-to-face interview; } \\
\text { Diagnostic Interview } \\
\text { Schedule (DIS-IIIA) }\end{array}$ & $\begin{array}{l}\text { Lifetime } \\
\text { prevalence }\end{array}$ & Inhibited orgasm (DSM-III criteria): $3.5 \%$ \\
\hline $\begin{array}{l}\text { Mercer et al., } \\
2003\end{array}$ & $\begin{array}{l}4,826 \text {; all had at } \\
\text { least } 1 \text { heterosexual } \\
\text { partner in last } 12 \\
\text { mos. }\end{array}$ & Britain & $16-44$ & $\begin{array}{l}\text { Computer-assisted self- } \\
\text { interview }\end{array}$ & Past 12 mos. & $\begin{array}{l}\text { Unable to experience orgasm: } \\
\text { Lasted at least } 1 \text { mo.: } 14.4 \% \\
\text { Lasted at least } 6 \text { mos.: } 3.7 \%\end{array}$ \\
\hline $\begin{array}{l}\text { Najman et al., } \\
2003\end{array}$ & 908 & Australia & $18-59$ & Telephone interview & $\begin{array}{l}\text { Several mos. } \\
\text { in the past } 12 \\
\text { mos. }\end{array}$ & $\begin{array}{l}\text { Trouble reaching orgasm: } 21-30 \% \\
\text { (depending on age) }\end{array}$ \\
\hline $\begin{array}{l}\text { Oberg et al., } \\
2004\end{array}$ & $\begin{array}{l}1,056, \text { all sexually } \\
\text { active during last } \\
12 \text { mos. }\end{array}$ & Sweden & $18-65$ & $\begin{array}{l}\text { Structured face-to-face } \\
\text { interview + questionnaires }\end{array}$ & Past 12 mos. & $\begin{array}{l}\text { Difficulties reaching orgasm: } \\
\text { Manifest": } 22 \% \text {; Mild: } 60 \%\end{array}$ \\
\hline
\end{tabular}




\begin{tabular}{|c|c|c|c|c|c|c|}
\hline $\begin{array}{l}\text { Richters et al., } \\
2003\end{array}$ & 9,134 & Australia & $16-59$ & $\begin{array}{l}\text { Computer-assisted } \\
\text { telephone interview }\end{array}$ & $\begin{array}{l}\text { At least } 1 \\
\text { month in the } \\
\text { past } 12 \text { mos. }\end{array}$ & Unable to experience orgasm: $28.6 \%$ \\
\hline $\begin{array}{l}\text { Spira et al., } \\
1994\end{array}$ & 1,137 & France & $18-69$ & Telephone interview & Lifetime & $\begin{array}{l}\text { Unable to experience orgasm: } \\
\text { Often: } 11 \% \\
\text { Sometimes: } 21 \%\end{array}$ \\
\hline $\begin{array}{l}\text { Ventegodt, } \\
1998\end{array}$ & 753 & Denmark & $18-88$ & Postal questionnaire & $\begin{array}{l}\text { Current } \\
\text { experience }\end{array}$ & Unable to experience orgasm: $6.8 \%$ \\
\hline $\begin{array}{l}\text { Witting et al., } \\
2008\end{array}$ & 5,463 women & Finland & $18-49$ & $\begin{array}{l}\text { Questionnaires (FSFI + } \\
\text { FSDS) }\end{array}$ & Past month & $\begin{array}{l}\text { Problems with orgasm (met FSFI cut-off } \\
\text { score of } 3.75 \text { ): } 31 \% \text {; } \\
\text { Met FSFI cut-off and reported distress: } \\
16 \%\end{array}$ \\
\hline
\end{tabular}

"Note: manifest = "quite often", "nearly all the time", and "all the time"; mild = "hardly ever" and "quite rarely". ** FSFI = Female Sexual Function Index (Rosen et al., 2000); FSDS = Female Sexual Distress Scale (Derogatis et al., 2002). 
Table 4.

Proposed Revision to DSM-IV Criteria for Female Orgasmic Disorder

A. At least one of the two following symptoms:

1. Delay in, or absence of, orgasm;

2. Markedly reduced intensity of orgasmic sensations.

B. Symptom(s) must have been present for at least six months and be experienced on $75 \%$ or more of occasions of sexual activity.

C. The problem causes marked distress or interpersonal difficulty.

Specify if: Lifelong vs. Acquired

Specify if: Generalized vs. Situational

Specify if: with concomitant problems in sexual interest/sexual arousal Dimensional Specifiers:

Relationship quality (if in a current relationship)

Distress experienced regarding symptoms 